\title{
Estimating the density of a small population of leopards (Panthera pardus) in central Iran using multi-session photographic-sampling data
}

\author{
Mohammad S. Farhadinia ${ }^{1,2} \cdot$ Pouyan Behnoud ${ }^{2} \cdot$ Kaveh Hobeali $^{2} \cdot$ Seyed Jalal Mousavi ${ }^{4}$. \\ Fatemeh Hosseini-Zavarei ${ }^{2} \cdot$ Navid Gholikhani $^{3} \cdot$ Hasan Akbari $^{5}$ - Alexander Braczkowski ${ }^{6}$ Morteza Eslami $^{3}$. \\ Peyman Moghadas ${ }^{2} \cdot$ David W. Macdonald $^{7}$
}

Received: 17 June 2020 / Accepted: 7 December 2020 / Published online: 8 January 2021

(c) The Author(s) 2021

\begin{abstract}
West Asian drylands host a number of threatened large carnivores, including the leopard (Panthera pardus) which is limited generally to areas with low primary productivity. While conservation efforts have focused on these areas for several decades, reliable population density estimates are missing for many of them. Spatially explicit capture-recapture (SECR) methodology is a widely accepted population density estimation tool to monitor populations of large carnivores and it incorporates animal movement in the statistical estimation process. We employed multi-session maximum-likelihood SECR modeling to estimate the density of a small population of leopard in a mountainous environment surrounded by deserts in central Iran. During 6724 camera trap nights, we detected 8 and 5 independent leopards in 2012 and 2016 sessions, respectively. The top-performing model produced density estimates of $1.6(95 \% \mathrm{CI}=0.9-2.9)$ and $1.0(95 \% \mathrm{CI}=0.6-1.6)$ independent leopards $/ 100 \mathrm{~km}^{2}$ in 2012 and 2016, respectively. Both sex and season had substantial effects on spatial scale $(\sigma)$, with larger movements recorded for males, and during winter. The estimates from our density estimation exercise represent some of the lowest densities across the leopard global range and strengthen the notion that arid habitats support low densities of the species. These small populations are vulnerable to demographic stochasticity, and monitoring temporal changes in their population density and composition is a critical tool in assisting conservation managers to better understand their population performance.
\end{abstract}

Keywords Bafq protected area $\cdot$ Maximum likelihood spatially explicit capture-recapture $\cdot$ Mountainous areas $\cdot$ Multisession $\cdot$ Panthera pardus $\cdot$ Small population

Handling editor: Michael Somers.

Supplementary Information The online version contains supplementary material available at https://doi.org/10.1007/s4299 1-020-00096-w.

Mohammad S. Farhadinia

mohammad.farhadinia@zoo.ox.ac.uk

1 Oxford Martin School and Department of Zoology, University of Oxford, 34 Broad Street, Oxford OX1 3BD, $\mathrm{UK}$

2 Future4Leopards Foundation, Tehran, Iran

3 Iranian Cheetah Society (ICS), P.O.Box 14155-8549, Tehran, Iran

\section{Introduction}

The monitoring of large carnivores living in mountainous ecosystems is a formidable challenge for conservationists and managers. For example, carnivores inhabiting mountainous landscapes tend to persist at lower densities than carnivores in lowland habitats (Alexander et al. 2015; Ghoddousi

4 Yazd Provincial Office of Department of the Environment, Yazd, Iran

5 South Khorasan Provincial Office of Department of the Environment, Birjand, Iran

6 Resilient Conservation, Environmental Futures Research Institute, Griffith University, Nathan, QLD 4111, Australia

7 Wildlife Conservation Research Unit, University of Oxford, Tubney House, Oxfordshire,, Oxford OX13 5QL, UK 
et al. 2010; Kachel et al. 2017) and have large movements and home ranges (Cheraghi et al. 2019; Farhadinia et al. 2018b; Johansson et al. 2016). Spatially explicit capture recapture (SECR) models are widely used to monitor populations of large carnivores (Sharma et al. 2014; Sollmann et al. 2013). SECR models incorporate spatial locations of captures within a unified model to provide reliable estimates of density (Borchers and Efford 2008; Efford 2004). They estimate animal density from a set of individual animal detections made at capture locations, for example by means of motion-detector camera traps, nested within a broader network of potential home-range centers (Efford 2004).

However, when the population size is small, several challenges arise for SECR density estimates (Gerber et al. 2014). Most importantly, infrequent detections (Mohamed et al. 2019; Rostro-García et al. 2018), the low number of individuals detected (Hearn et al. 2017; Sharma et al. 2014) and variability in detection among individuals (Alexander et al. 2015; Gerber et al. 2014) can compromise SECR models' precision. The SECR method also requires sampling to be conducted relatively densely to obtain sufficient recaptures of individuals on multiple cameras; this is required for adequate estimates of the spatial scale parameter $(\sigma)$ (Sollmann et al. 2013; Wilton et al. 2014).

Nonetheless, SECR models perform well for species with large home ranges that are present at low densities if some realistic requirements are met (Wilton et al. 2014; Zimmermann and Foresti 2016). First, the extent of the detector array has to be similar or larger than the extent of individual movement (Efford 2011; Sollmann et al. 2012). Second, the optimal distance between traps is twice as large as the $\sigma$ (Sollmann et al. 2012; Sun et al. 2014). Third, repeat detections should exceed 20 (Efford 2011), and finally, each individual should be detected on average at least 2.5 times (Gerber et al. 2014). Importantly, sharing detection information across time and space (Gerber et al. 2014; Morehouse and Boyce 2016) can increase the precision of density estimates. However, when landscape features restrict the spatial arrangement of detectors, notably in mountainous areas, biologists inevitably select small-sized study areas, usually in good quality habitats, which can result in violating some of the above requirements (Suryawanshi et al. 2019).

Asian mountains harbor large felids with large spatial requirements, such as common leopards (Panthera par$d u s$ ) and snow leopard (P. uncia) (Farhadinia et al. 2018b; Johansson et al. 2016). Hence, most population estimates of large felids in mountainous areas, based on SECR photographic data, come from study areas that are small relative to the species home range (Alexander et al. 2015; Farhadinia et al. 2019; Kachel et al. 2017; Suryawanshi et al. 2019), usually with small populations of fewer than ten individuals (Ghoddousi et al. 2010; Kachel et al. 2017; McCarthy et al. 2008). Their rarity and potential vulnerability of these populations to demographic stochasticity underscores the critical and time-sensitive need to develop efficient analytical methods to track their populations robustly over time (Karanth et al. 2006).

In this study, we employed multi-session SECR modeling to understand the population density and composition of Persian leopards ( $P$. p. saxicolor) in a mountainous desert environment in central Iran. We expected that leopards would show inter-seasonal variation in density parameters, with larger movements in winter than summer. Our study provides the first population density estimate of leopards from the driest area in which they have ever been studied globally.

\section{Materials and methods}

\section{Study area}

We implemented our study in the Bafq Protected Area (hereafter Bafq) of central Iran $\left(31.5023^{\circ} \mathrm{N}, 55.7134^{\circ} \mathrm{E}\right)$. Bafq was designated a protected area in 1996, near the city of Bafq in central Iran. With an area of $885 \mathrm{~km}^{2}$, Bafq is an arid mountainous region typified by sparse plains and rolling hills (Fig. 1). The altitude range varies between 1060 and $2860 \mathrm{~m}$ above sea level and mean annual precipitation is $70 \mathrm{~mm}$ (Sohrabinia and Hosseini-Zaverei 2010). Springs, wells, air pumps and small dams constructed at high altitude are the main water supplies in the region. There are four main villages inside the area. Anti-poaching law enforcement is carried out by 13 rangers.

\section{Sampling design}

We deployed camera trap stations (Panthera ${ }^{\circledR}$ IV and V (New York, NY 10,018, USA) and Cuddeback Capture Model 1125 (Non Typical, Inc., Park Falls, WI, USA), all working with white Xenon flashes) on park-wide $4 \times 4 \mathrm{~km}$ grids to ensure even coverage of the whole study area (Fig. 1) for 88 and 91 days in winter 2011-2012 and summer-autumn 2016 within Bafq, respectively (Table 1). Short sampling periods ( $\leq 3$ months) are necessary to avoid violating the assumption of demographic closure (Zimmermann and Foresti 2016). In winter 2011-2012, camera traps were placed either along trails or dirt roads as these are regularly traversed by leopards (Farhadinia et al. 2019). In 2016, when the survey was conducted during the driest months of the year (August-October), we equipped 38 water resources (springs or artificial waterholes, 58\% of stations) with a camera trap, additional to the trails ( $n=28,42 \%$ of stations), predominantly along valley bottoms or trails. Camera stations were placed at a mean spacing of 1620 and $1409 \mathrm{~m}$ in the two consecutive sessions to simultaneously achieve the twin objectives of maximizing the number of individuals 
Fig. 1 Spatial configuration of study areas and locations of camera trap stations across the two sessions in Bafq Protected Area, central Iran. The map inset shows locations of the study area in Iran

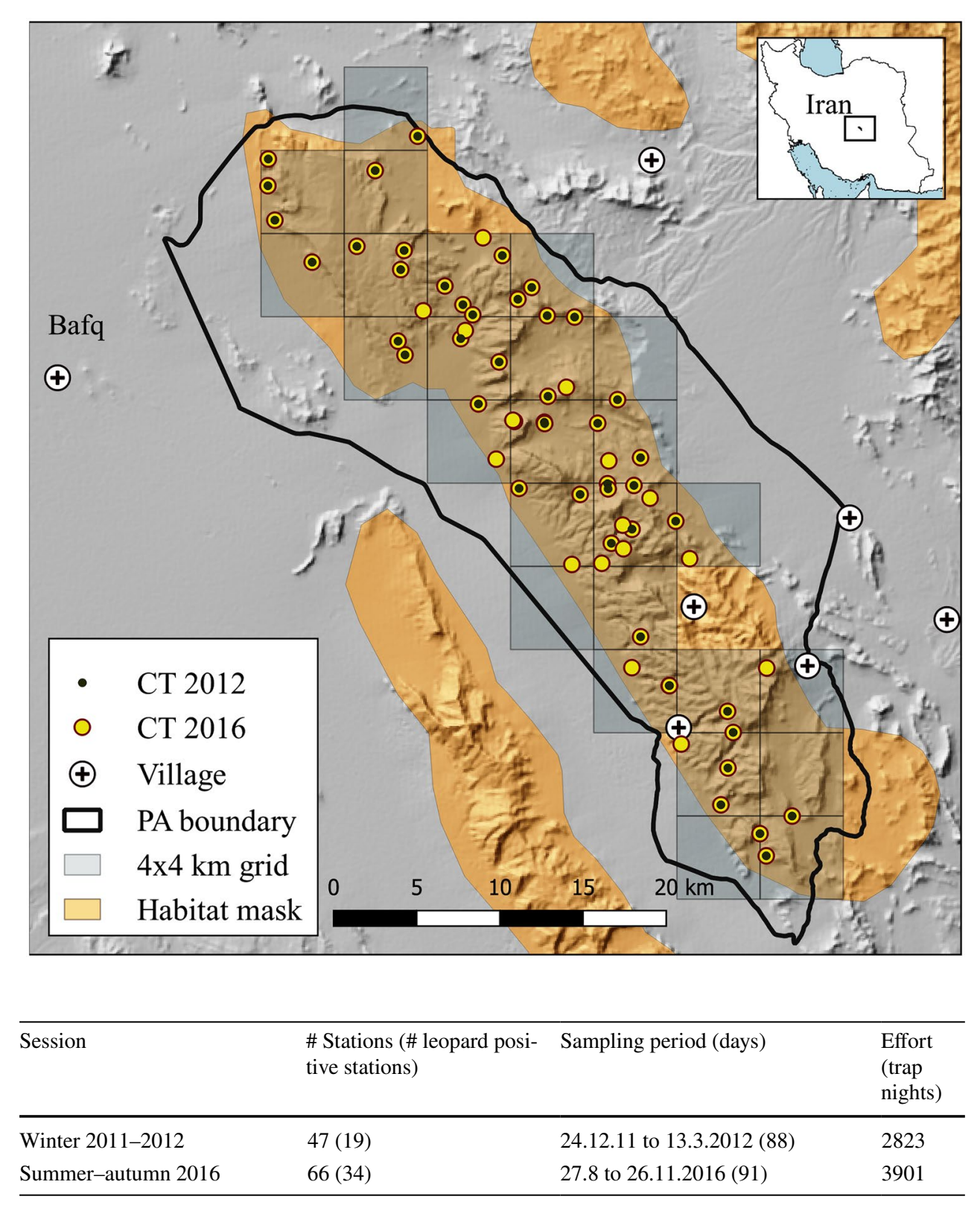

\begin{tabular}{llll}
\hline Session & $\begin{array}{l}\text { \# Stations (\# leopard posi- } \\
\text { tive stations) }\end{array}$ & Sampling period (days) & $\begin{array}{l}\text { Effort } \\
\text { (trap } \\
\text { nights) }\end{array}$ \\
\hline Winter 2011-2012 & $47(19)$ & 24.12 .11 to 13.3.2012 (88) & 2823 \\
Summer-autumn 2016 & $66(34)$ & 27.8 to 26.11.2016 (91) & 3901 \\
\hline
\end{tabular}

Table 1 Details of sampling design for the multi-session spatially explicit capturerecapture framework in Bafq Protected Area (2011-2012 and 2016) caught and adequately recapturing individuals at different camera traps, as required in SECR designs. A total of 22 and 26 grids were sampled during the 2 sessions, respectively (Fig. 1).

\section{Data analysis}

We considered each 24-h day as a sampling occasion. All consecutive photographs of the same individual taken no more than $0.5 \mathrm{~h}$ apart were defined as a single event (Braczkowski et al. 2016). The identity of leopards was determined by the unique rosette patterns on their pelage, independently by two researchers (PB and MSF), and individuals were only included in the analysis if consensus on individuals was achieved by both observers. The sex of individual leopards was determined where possible from sex-specific cues, such as visible genitalia, the presence of dependent individuals. We only included independent individuals, including adults and sub-adults, in the analysis. Dependent cubs were excluded from the SECR modeling.

We estimated the density of leopards using a maximumlikelihood SECR approach (Borchers and Efford 2008) using the package 'secr' version 3.2 (Efford 2019) in the $R$ software version 3.3.3. (R Development Core Team 2013). The estimates of population density produced by SECR are less sensitive to the edge effects of traditional non-spatial estimators, incomplete detection and heterogeneous capture probabilities, and eliminate the need for an 
ad hoc estimation of the sampling area (Efford 2004). The secr package also allowed us to evaluate the effect of sex on density parameters.

We combined the 2 years into a single model framework and considered each year as an independent session. For each 'session', secr modeling assumes a new realization of the underlying population process (Efford 2019). The multisession analysis enables the fitting of models with parameter values that apply across sessions, and the data are then effectively pooled with respect to those parameters. Our two sessions did not overlap temporally and only one individual (F2) was observed in both sessions, ensuring that the independence assumption between the sessions was not violated.

We used a hierarchical model composed of an explicit state-space process model and an observation model (Efford 2004). The animal population size and their respective central locations ("home-range centers") constitute the statespace process, assuming a Poisson distribution (Borchers and Efford 2008; Efford 2004). The observation model describes the probability of encounter as a function of an individual's location at the time of sample, and a probability of "count" detector parameter (Efford, 2017). The half-normal detection function contains two parameters: $g_{0}$, which is the baseline detection rate when the distance between the animal's activity centers and the camera traps is zero; and $\sigma$, which is the spatial scale parameter (with the unit of meters) of the encounter probability model (Borchers and Efford 2008; Efford 2004).
We defined the area of integration (i.e., state-space model) by equally spaced points in a regular grid, with a mesh spacing of $1 \mathrm{~km}^{2}$. A buffer was plotted around the detector array to incorporate individuals with activity centers outside of the trapping area, but whose movement range extends into the sampling area (Borchers and Efford 2008; Efford 2004). We used a mask with a buffer of $120 \mathrm{~km}$ to define the outer limit of the state-space area. This buffer size (3-4 times $\sigma$ ) corresponds to an area beyond which the animals would have a low probability of being detected, and thus was unlikely to influence density estimates (Efford 2004). As leopards are unlikely to have their home-range centers in these areas of low productivity or increased conflict (Braczkowski et al. 2016; Farhadinia et al. 2019), areas such as villages, open deserts and sand dunes were masked out from the effective area, based on an ensemble suitability map developed by Ahmadi et al. (2020).

For our models of density estimation, we fitted 14 a priori models with varying effects on $g_{0}$ and $\sigma$ in a multi-session framework (Table 2). We included a trap-specific behavioral response in the baseline detection model because we expected that the leopard behavior to change after being detected at a specific trap for the duration of the session (bk). Large terrestrial carnivores typically feature differences in their home-range sizes, movement patterns and capture probability (Farhadinia et al. 2019; Sharma et al. 2014). This can affect the observation process in capture-recapture exercises (Sollmann et al. 2013). SECR is considered a robust method for calculating animal densities because it accounts
Table 2 Model selection results for 2 sets of 14 fitted multisession models (totaling 28 models) ranked by Akaike's Information Criterion corrected for the small samples (AICc) for 2012 and 2016 Persian leopard density Bafq Protected Area, central Iran

\begin{tabular}{lllll}
\hline Model description & Parameters $^{\mathrm{a}}$ & AICc & $\Delta$ AICc $^{\mathrm{b}}$ & AICc weight $^{\mathrm{c}}$ \\
\hline$g_{0} \sim(\mathrm{bk}+$ session + Sex $)$ sigma $\sim($ Sex + session $)$ & 7 & 1830.6 & 0.0 & 0.87 \\
$g_{0} \sim$ bk sigma $\sim$ session & 4 & 1835.9 & 5.2 & 0.06 \\
$g_{0} \sim($ Sex + session) sigma $\sim($ Sex + session $)$ & 6 & 1837.1 & 6.5 & 0.03 \\
$g_{0} \sim($ bk + session) sigma $\sim$ session & 5 & 1838.3 & 7.7 & 0.02 \\
$g_{0} \sim$ bk sigma $\sim 1$ & 3 & 1839.7 & 9.1 & 0.01 \\
$g_{0} \sim($ Sex + bk) sigma $\sim$ session & 5 & 1841.4 & 10.7 & 0 \\
$g_{0} \sim 1$ sigma $\sim($ Sex + session $)$ & 4 & 1855.7 & 25.0 & 0 \\
$g_{0} \sim$ session sigma $\sim$ session & 4 & 1862.4 & 31.7 & 0 \\
$g_{0} \sim$ Sex sigma $\sim$ Sex & 4 & 1864.5 & 33.9 & 0 \\
$g_{0} \sim($ Sex + session) sigma $\sim$ session & 5 & 1865.5 & 34.8 & 0 \\
$g_{0} \sim 1$ sigma $\sim$ Sex & 3 & 1875.5 & 44.9 & 0 \\
$g_{0} \sim($ Sex + session $)$ sigma $\sim 1$ & 4 & 1876.1 & 45.5 & 0 \\
$g_{0} \sim$ Sex sigma $\sim 1$ & 3 & 1884.1 & 53.5 & 0 \\
$g_{0} \sim 1$ sigma $\sim 1$ & 2 & 1886.2 & 55.5 & 0 \\
\hline
\end{tabular}

We fitted models using the half-normal detection function. $g_{0}=$ baseline detection rate at trap location considered as home-range center; and sigma $(\sigma)=$ spatial scale parameter. Effects on $g_{0}$ and $\sigma$ included sex (Sex), session (session) and behavioral response (bk)

${ }^{a}$ Number of model parameters

${ }^{\mathrm{b}}$ Difference in AICc score compared with the smallest AICc score

${ }^{\mathrm{c}}$ AICc model weight 


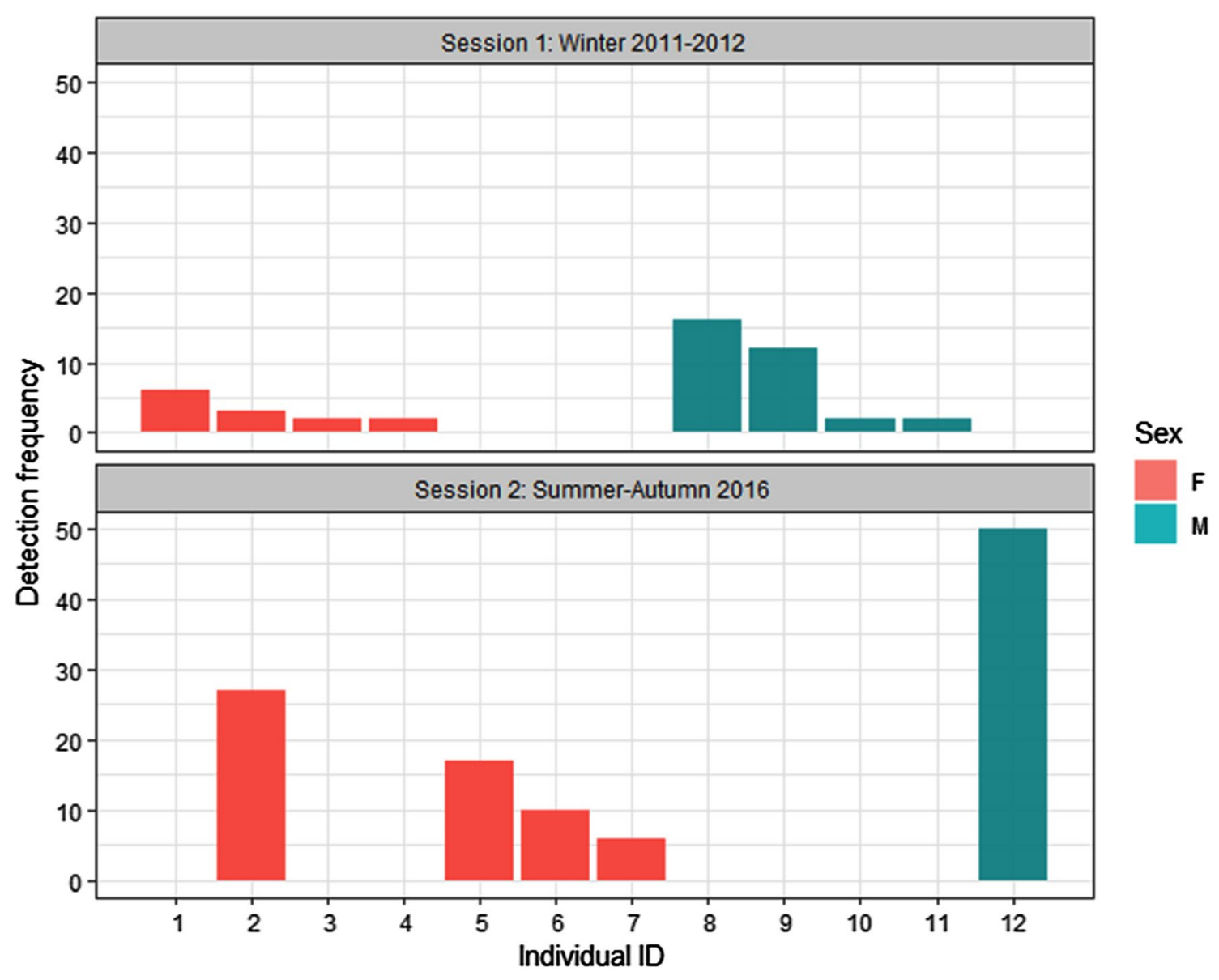

Fig. 2 Comparison of detection frequency for all demographic classes between winter 2011-2012 and summer-autumn 2016 sessions in Bafq Protected Area, central Iran. Each code on the $x$-axis refers to a single individual leopard. Only one individual (F2) was detected in both sessions

for individual heterogeneity due to space usage (whereas non-spatial capture-recapture does not). To account for heterogeneous capture probability in leopards, we also included a sex-specific covariate in the observation process, which would account for different capture probabilities amongst males and females (Farhadinia et al. 2019). We included a sex-effect for the encounter rate $\left(g_{0}\right)$ and spatial scale $(\sigma)$, both of which are widely seen in leopard studies (Braczkowski et al. 2016; Goldberg et al. 2015; Rostro-García et al. 2018). We finally fitted session-stratified estimates, meaning that all parameters vary across sessions (i.e., years), by maximizing the likelihood. Akaike's Information Criterion corrected for the small samples (AICc) was used to identify the most parsimonious model (i.e., the lowest AICc score; (Burnham and Anderson 2002). The highest ranked model was used to estimate leopard density $(D)$, population size, detection rate at home-range center $\left(g_{0}\right)$ and $\sigma$. The population size was the number of individuals within the region for the current realization of the process (Efford 2017).

\section{Results}

\section{Photographic captures}

During a sampling period of 2823 trap nights in winter 2011-2012, we obtained a total of 49 independent leopard detections (events) of 8 independent leopard individuals. Five leopards were photographed on both flanks, two male leopards were photographed only on their right flank and one female leopard accompanied by a single cub was photographed only on its left flank. For analyses, we used eight different leopards, equally from each sex (Fig. 2). In summer-autumn 2016, we obtained 141 independent detections of leopards during 3901 trap nights (Table 3). Since 58\% of camera traps were deployed at water resources in the summer of 2016, leopards regularly turned their bodies which enabled us to photograph both flanks. From these detections, we were able to identify five independent individuals. They included only a single adult male and four adult females (Fig. 2). In each session, we also detected two leopard families with a total of three cubs (ranging 1-2 per 
Table 3 Details of baseline information on leopard based on systematic camera trapping across two sessions of winter 2011-2012 and summerautumn 2016

Session
\# Independent leopard detections

(\# non-identifiable)
\# Detected independ- Sex ratio (M:F) ent leopards
\# Families

Dependent cubs

Winter 2011-2012

45 (4)

$110(31)$

8
5

\begin{tabular}{l}
8 \\
5 \\
\hline
\end{tabular}

$1: 1$

$0.25: 1$

2

Independent leopards included adults and sub-adults. $\mathrm{M}=$ male, $\mathrm{F}=$ female and family = mother with dependent cub

family), resulting in a cumulative number of four families with six cubs for the study period.

Leopard detections were approximately three times more frequent at water-based cameras compared with trail-based stations comparing to proportions of each camera placement (105 vs. 36 independent detections; $X^{2}=5.2$, df $=1$, $P=0.02)$. The four independent females observed during the second session were detected only 1-4 times at trail-based camera traps, while they were more frequently seen at water resources, varying between 5 and 24 detections. During the winter session, same-trap recapture was rare $(10 \%$ of total detections) whereas it increased to $27 \%$ of detections during the summer session. Male leopards showed large-scale movements relative to the size of the detector array.

\section{Density estimation}

There was strong support for one model based on the AICc (Table 2), defined as $g_{0} \sim \mathrm{bk}+\operatorname{session}+\operatorname{sex} \sigma \sim \operatorname{session}+\operatorname{sex}$. We found sex and session-specific variability in spatial scale $(\sigma)$. Males had larger $\sigma$ than females in each session, yielding an inter-sexual ratio of 1.6 (Table 4), indicating large spatial movements of male leopards throughout Bafq. Likewise, although $\sigma$ estimates were overlapping in their $95 \%$ confidence intervals between the two seasons for each sex, the mean estimates of $\sigma$ for the winter session were 1.5 larger than summer-autumn session, regardless of the sex (Table 2). This suggests less mobility of leopards during warm months.

The top model also supported sex and session-specific baseline detection rates $\left(g_{0}\right)$. Thus, the $g_{0}$ estimates showed substantial inter-sessional difference for each sex, increasing by a magnitude of 21.4-30.0 from the winter to summer-autumn sessions (Table 2). For all sex groups within a session, $g_{0 b k=1}$ was larger than $g_{0 b k=0}$ with a ratio of 3.2-4.3 between the means. The bk effect tested the hypothesis that leopard behavior changes after being detected at a specific site for the duration of the survey (trap response). Therefore, when a leopard was detected in a specific camera trap site, the probability of a subsequent encounter for the entire survey was increased, i.e., the individual became 'trap happy' at the population level (beta coefficient $g_{0 \mathrm{bk}}=1.4,95 \% \mathrm{CI}=0.9-1.8$ ).

The best performing model estimated a density of 1.6 (95\% CI $=0.9-2.9)$ and $1.0(95 \% \mathrm{CI}=0.6-1.6)$ independent
Table 4 Density estimates of Persian leopards with standard error (SE) and 95\% confidence interval (lower and upper) of parameters for spatially explicit capture-recapture models fit to camera trapping data from Bafq Protected Area, central Iran

\begin{tabular}{|c|c|c|c|c|}
\hline Parameter & Estimate & SE & Lower CI & Upper CI \\
\hline \multicolumn{5}{|c|}{ Session 1: winter 2011-2012 } \\
\hline$D$ & 1.6 & 0.5 & 0.9 & 2.9 \\
\hline \multicolumn{5}{|l|}{ Female } \\
\hline$g_{0 b k=0}$ & 0.003 & 0.003 & 0.001 & 0.020 \\
\hline$g_{0 b k=1}$ & 0.013 & 0.011 & 0.003 & 0.064 \\
\hline$\sigma$ & 34,500 & 12,000 & 17,800 & 67,000 \\
\hline \multicolumn{5}{|l|}{ Male } \\
\hline$g_{0 b k=0}$ & 0.004 & 0.001 & 0.002 & 0.007 \\
\hline$g_{0 b k=1}$ & 0.015 & 0.005 & 0.008 & 0.028 \\
\hline$\sigma$ & 54,000 & 16,000 & 30,900 & 95,530 \\
\hline \multicolumn{5}{|c|}{ Session 2: summer-autumn 2016} \\
\hline$D$ & 1.0 & 0.3 & 0.6 & 1.6 \\
\hline \multicolumn{5}{|l|}{ Female } \\
\hline$g_{0 b k=0}$ & 0.090 & 0.053 & 0.027 & 0.260 \\
\hline$g_{0 b k=1}$ & 0.290 & 0.140 & 0.096 & 0.604 \\
\hline$\sigma$ & 22,150 & 2300 & 18,100 & 27,100 \\
\hline \multicolumn{5}{|l|}{ Male } \\
\hline$g_{0 b k=0}$ & 0.102 & 0.093 & 0.015 & 0.453 \\
\hline$g_{0 b k=1}$ & 0.316 & 0.242 & 0.049 & 0.810 \\
\hline$\sigma$ & 35,000 & 6500 & 24,200 & 50,000 \\
\hline
\end{tabular}

Density $(D)$ is reported in independent leopards per $100 \mathrm{~km}^{2}$. The detection rate at trap location $\left(g_{0}\right)$ considered as home-range center and $\sigma$ is the scale of an individual's movement distribution (m). The $g_{0 \quad b k=0}$ corresponds to the naive state whereas the $g_{0 b k=l}$ represents learned response

leopards $/ 100 \mathrm{~km}^{2}$ for the first and second sessions, respectively (Table 4). A total of 10.9 \pm SE 3.4 independent leopards were estimated for the winter 2011-2012 while the population size was calculated as $6.9 \pm$ SE 1.8 independent leopards for the 2016 session.

\section{Discussion}

We estimated the density of leopards from the driest known study site of the species global distribution, with an average annual precipitation of $70 \mathrm{~mm}$ (Sohrabinia and 
Hosseini-Zaverei 2010). Although data on leopard density estimates in arid regions are sparse, they, including the present data, indicate some of the lowest densities across the leopard global range, all below 2 adults per $100 \mathrm{~km}^{2}$ (Edwards et al. 2016; Ghoddousi et al. 2010; Mann et al. 2020; Stein et al. 2011).

\section{Density patterns of leopards over time}

Temporal changes in population density and composition in Bafq's leopards support two types of variation. First, substantial overlap in confidence intervals between the two sessions suggested that the different density point estimates could be due to sampling variation, i.e., variation in a statistic from sample to sample, which is commonly seen in multi-session SECR studies of leopards (Rogan et al. 2019; Rosenblatt et al. 2016). Second, detection of only one individual in both sessions (4 years apart; Fig. 2) suggested that despite the observed overlap between the large confidence intervals, density variation, i.e., real population differences, cannot be totally rejected.

Accordingly, there are three possible reasons to explain observed variations between the two sessions. First, prey density as the main bottom-up driving process of carnivore populations can shape leopard demography (Ramesh et al. 2017; Strampelli et al. 2018). We obtained annual census data of ungulates in the study area for the period between 2011 and 2016, conducted by Yazd Provincial Office of the Department of the Environment every November using 10-15 groups of field staff (Table S1). These census data suggested that the population size for bezoar goat Capra aegagrus and urial Ovis vignei, two key prey for Persian leopards (Farhadinia et al. 2018a; Rezaei et al. 2016), was not decreasing.

Second, top-down regulation due to human persecution, particularly due to conflict with human communities can cause high anthropogenic mortality (Rosenblatt et al. 2016; Rostro-García et al. 2018; Sharma et al. 2014). A dietary investigation, based on fecal analysis, found only $7.54 \%$ of the total leopard diet (expressed as biomass consumed) to be composed of domestic animals in Bafq (Rezaei et al. 2016). Equally important, only one record of an individual poisoned between the two survey efforts was obtained (Seyed Jalal Mousavi, pers.obs). Unlike many parts of the leopard range in west Asia where conflict with human communities is a major source of concern (Babrgir et al. 2017; Khorozyan et al. 2020; Sharbafi et al. 2016), we found little evidence, based on poaching records and dietary analysis, that the Bafq leopard population suffers direct anthropogenic persecution. Nonetheless, almost no replication in leopard individuals between the two sessions suggests that the real anthropogenic mortality of leopards is likely to be higher than what was detected.

Finally, emigration can affect the demography of large felids (Fattebert et al. 2015; Sharma et al. 2014). Persian leopards can disperse up to $80 \mathrm{~km}$ (Farhadinia et al. 2018b), implying that many surrounding scattered mountains around Bafq can be potentially visited by leopards. We expect that emigrated individuals have much less chance of survival due to a lower level of law enforcement, if any, outside Bafq Protected Area.

In conclusion, we expect that additive effects of sampling variation (because of different seasons and sessions) and density variation (mostly due to human persecution and emigration) resulted in the observed density pattern over time. However, the small sample sizes and a lack of further replications requires us to view our findings as suggestive rather than conclusive, and to concede that further research is necessary to assess the demographic trends of leopards in central Iran.

\section{Seasonality and conservation implications}

Importantly, season had a strong effect on baseline detection rate $\left(g_{0}\right)$ and spatial scale $(\sigma)$, both of which influence the density estimate. Nonetheless, season can have confounding effects with year. Larger $\sigma$ during winter (2011-2012) suggested a higher mobility of leopards preceding and during the mating season, which peaks in mid-winter (Farhadinia et al. 2018b). In contrast, water resources are crucial for leopards in warm seasons, not only to meet their drinking requirements, but to optimize their encounter rate with prey (Farhadinia et al. 2018a). This results in smaller $\sigma$ and larger $g_{0}$ in the warmer months of the year. In addition, leopards exhibited an increased tendency to revisit camera trap stations, a result that is unsurprising when $58 \%$ of traps are at water resources and successive captures are not independent. In addition to season, leopard populations may exhibit marked inter-annual variation in $\sigma$ (Rogan et al. 2019; Rosenblatt et al. 2016), possibly due to their dynamic spatial patterns and home-range sizes.

Population monitoring of large carnivores, particularly in remote montane landscapes, represents a considerable conservation challenge (Farhadinia et al. 2018c; Suryawanshi et al. 2019). The concentration of cameras around water resources in hot months can result in a higher recapture rate and consequently higher precision in density estimates. Future studies are encouraged to investigate the potential advantages and disadvantages of preferential water-based sampling on density estimation. Finally, season can have strong effects on parameters for SECR models in mountainous areas with remarkable seasonal pattern. A multi-session SECR framework can enhance accuracy of density parameters. 
The persistence of small leopard populations can be adversely affected by demographic stochasticity through reducing survival and fecundity (Rostro-García et al. 2018; Williams et al. 2017). Importantly, controlling two threats, prey depletion and leopard persecution in nearby areas to support individuals dispersing from this breeding population are crucial for the future persistence of this population. In addition to single density estimates, temporal changes in population density and composition, similar to those we provide here are helpful to inform data-driven decision-making processes to define conservation action priorities. Most importantly, and to the best of our knowledge, no study prior to ours has assessed the demographic trends of leopards, and other large carnivores inhabiting the remote drylands of the Middle East. Our study has provided an important and first step in addressing this knowledge gap, and this is essential for the future management and conservation of leopards.

Acknowledgements We sincerely thank the Iranian Department of Environment for administrative support and provision of necessary permissions. Financial support was provided by Conservation of Asiatic Cheetah Project, Yazd Provincial Office of Department of the Environment, Idea Wild, Dieren Park Amersfoort Wildlife Fund and Rufford Foundation. E. Horstman and A. Morehouse advised on data analyses, and P. Johnson and L. Sousa commented on an earlier version of this manuscript. A. Rezaei, A. Bakhtiari, H. Alizadeh, M. Mirhodaie, B. Tavakoli, H. Akhoundi, O. Fotouhi, A. Mosalman, E. Hasannezhad, M. Khajeh, Asghar Khajeh, J. Tafakori and Ali Khajeh assisted in field sampling. We are particularly grateful to the support and dedication of the Bafq's rangers.

Data availability Datasets analyzed during the current study are available on Figshare with the generated link as (https://figshare.com/s/98ca1 dc84ffc861dbed7).

Open Access This article is licensed under a Creative Commons Attribution 4.0 International License, which permits use, sharing, adaptation, distribution and reproduction in any medium or format, as long as you give appropriate credit to the original author(s) and the source, provide a link to the Creative Commons licence, and indicate if changes were made. The images or other third party material in this article are included in the article's Creative Commons licence, unless indicated otherwise in a credit line to the material. If material is not included in the article's Creative Commons licence and your intended use is not permitted by statutory regulation or exceeds the permitted use, you will need to obtain permission directly from the copyright holder. To view a copy of this licence, visit http://creativecommons.org/licenses/by/4.0/.

\section{References}

Ahmadi M, Farhadinia MS, Cushman SAM, Balouchi MR, Nezami B, Jowkar H (2020) Species and space: a combined gap analysis to guide management planning of conservation areas. Landsc Ecol $35: 1505-1517$
Alexander JS, Gopalaswamy AM, Shi K, Riordan P (2015) Face value: towards robust estimates of snow leopard densities. PLoS ONE 10:e0134815

Babrgir S, Farhadinia MS, Moqanaki EM (2017) Socio-economic consequences of cattle predation by the Endangered Persian leopard Panthera pardus saxicolor in a Caucasian conflict hotspot, northern Iran. Oryx 51:124-130

Borchers DL, Efford MG (2008) Spatially explicit maximum likelihood methods for capture-recapture studies. Biometrics 64:377-385

Braczkowski AR, Balme GA, Dickman A, Fattebert J, Johnson PJ, Dickerson T, Macdonald DW, Hunter LTB (2016) Scent lure effect on camera-trap based leopard density estimates. PLoS ONE 11:e0151033

Burnham KP, Anderson DR (2002) Model selection and multimodel inference: a practical information-theoretic approach, 2nd edn. Springer, New York

Cheraghi F, Delavar MR, Amiraslani F, Alavipanah K, Gurarie E, Jowkar H, Hunter L, Ostrowski S, Fagan WF (2019) Interdependent movements of Asiatic Cheetahs Acinonyx jubatusvenaticus and a Persian Leopard Panthera pardussaxicolor in a desert environment in Iran (Mammalia: Felidae). Zool Middle East 65:283-292

Edwards S, Aschenborn O, Gange AC, Wiesel I (2016) Leopard density estimates from semi-desert commercial farmlands, southwest Namibia. Afr J Ecol 54:103-106

Efford MG (2004) Density estimation in live-trapping studies. Oikos 106:598-610

Efford MG (2011) Estimation of population density by spatially explicit capture-recapture analysis of data from area searches. Ecology 92:2202-2207

Efford MG (2017) secr: Spatially explicit capture-recapture models. $\mathrm{R}$ package version 3.0.1

Efford MG (2019) Multi-session models in secr 3.2

Farhadinia MS, Johnson PJ, Hunter LTB, Macdonald DW (2018a) Persian leopard predation patterns and kill rates in the IranTurkmenistan borderland. J Mammal 99:713-723

Farhadinia MS, Johnson PJ, Macdonald DW, Hunter LTB (2018b) Anchoring and adjusting amidst humans: ranging behavior of Persian leopards along the Iran-Turkmenistan borderland. PLoS ONE 13:e0196602

Farhadinia MS, Moll RJ, Montgomery RA, Ashrafi S, Johnson PJ, Hunter LTB, Macdonald DW (2018c) Citizen science data facilitate monitoring of rare large carnivores in remote montane landscapes. Ecol Indic 94:283-291

Farhadinia MS, McClintock BT, Johnson PJ, Behnoud P, Hobeali K, Moghadas P, Hunter LTB, Macdonald DW (2019) A paradox of local abundance amidst regional rarity: the value of montane refugia for Persian leopard conservation. Sci Rep 9:14622

Fattebert J, Balme GA, Dickerson T, Slotow R, Hunter LTB (2015) Density-dependent natal dispersal patterns in a leopard population recovering from over-harvest. PLoS ONE 10:e0122355

Gerber BD, Ivan JS, Burnham KP (2014) Estimating the abundance of rare and elusive carnivores from photographic-sampling data when the population size is very small. Popul Ecol 56:463-470

Ghoddousi A, Hamidi AK, Ghadirian T, Ashayeri D, Khorozyan I (2010) The status of the endangered Persian leopard Panthera pardussaxicolor in Bamu National Park. Iran Oryx 44:551-557

Goldberg JF, Tempa T, Norbu N, Hebblewhite M, Mills LS, Wangchuk TR, Lukacs P (2015) Examining temporal sample scale and model choice with spatial capture-recapture models in the common leopard Panthera pardus. PLoS ONE 10:e0140757

Hearn AJ, Ross J, Bernard H, Bakar SA, Goossens B, Hunter LTB, Macdonald DW (2017) Responses of Sunda clouded leopard Neofelis diardi population density to anthropogenic disturbance: refining estimates of its conservation status in Sabah. Oryx 53:643-653 
Johansson Ö, Rauset GR, Samelius G, McCarthy T, Andrén H, Tumursukh L, Mishra C (2016) Land sharing is essential for snow leopard conservation. Biol Conserv 203:1-7

Kachel SM, McCarthy KP, McCarthy TM, Oshurmamadov N (2017) Investigating the potential impact of trophy hunting of wild ungulates on snow leopard Panthera uncia conservation in Tajikistan. Oryx 51:597-604

Karanth KU, Nichols JD, Kumar NS, Hines JE (2006) Assessing tiger population dynamics using photographic capture-recapture sampling. Ecology 87:2925-2937

Khorozyan I, Ghoddousi S, Soufi M, Soofi M, Waltert M (2020) Studded leather collars are very effective in protecting cattle from leopard (Panthera pardus) attacks. Ecol Solut Evid 1:e12013

Mann GKH, O'Riain MJ, Parker DM (2020) A leopard's favourite spots: habitat preference and population density of leopards in a semi-arid biodiversity hotspot. J Arid Environ 181:104218

McCarthy K, Fuller TK, Ming M, McCarthy TM, Waits L, Jumabaev K (2008) Assessing estimators of snow leopard abundance. J Wildl Manage 72:1826-1833

Mohamed A, Sollmann R, Wong ST, Niedballa J, Abrams JF, Kissing J, Wilting A (2019) Counting Sunda clouded leopards with confidence: incorporating individual heterogeneity in density estimates. Oryx $1-10$

Morehouse AT, Boyce MS (2016) Grizzly bears without borders: spatially explicit capture-recapture in southwestern Alberta. J Wildl Manage 80:1152-1166

R Development Core Team, 2013. R: A language and environment for statistical computing

Ramesh T, Kalle R, Rosenlund H, Downs CT (2017) Low leopard populations in protected areas of Maputaland: a consequence of poaching, habitat condition, abundance of prey, and a top predator. Ecol Evol 7:1964-1973

Rezaei R, Kaboli M, Ashrafi S, Akbari H (2016) Food niche of Persian leopard in Bafq Protected Area. Q J Anim Environ 8:1-8

Rogan MS, Balme GA, Distiller G, Pitman RT, Broadfield J, Mann GKH, Whittington-Jones GM, Thomas LH, O'Riain MJ (2019) The influence of movement on the occupancy-density relationship at small spatial scales. Ecosphere 10:e2807

Rosenblatt E, Creel S, Becker MS, Merkle J, Mwape H, Schuette P, Simpamba T (2016) Effects of a protection gradient on carnivore density and survival: an example with leopards in the Luangwa valley. Zambia Ecol Evol 6:3772-3785

Rostro-García S, Kamler JF, Crouthers R, Sopheak K, Prum S, In V, Pin C, Caragiulo A, Macdonald DW (2018) An adaptable but threatened big cat: density, diet and prey selection of the
Indochinese leopard (Panthera pardus delacouri) in eastern Cambodia. R. Soc. Open Sci. 5

Sharbafi E, Farhadinia MS, Rezaie HR, Braczkowski AR (2016) Prey of the Persian Leopard (Panthera pardussaxicolor) in a mixed forest-steppe landscape in northeastern Iran (Mammalia: Felidae). Zool Middle East 62:1-8

Sharma K, Bayrakcismith R, Tumursukh L, Johansson O, Sevger P, McCarthy T, Mishra C (2014) Vigorous dynamics underlie a stable population of the endangered snow leopard Panthera uncia in Tost mountains, south Gobi. Mongolia PLoS One 9:e101319

Sohrabinia S, Hosseini-Zaverei F (2010) Bafq Protected Area. Zeytoun Publishing Company

Sollmann R, Gardner B, Belant JL (2012) How does spatial study design influence density estimates from spatial capture-recapture models? PLoS ONE 7(4):e34575

Sollmann R, Tôrres NM, Furtado MM, de Almeida Jácomo AT, Palomares F, Roques S, Silveira L (2013) Combining camera-trapping and noninvasive genetic data in a spatial capture-recapture framework improves density estimates for the jaguar. Biol Conserv 167:242-247

Stein AB, Fuller TK, DeStefano S, Marker L (2011) Leopard population and home range estimates in north-central Namibia. Afr $\mathrm{J}$ Ecol 49:383-387

Strampelli P, Andresen L, Everatt KT, Somers MJ, Rowcliffe JM (2018) Habitat use responses of the African leopard in a humandisturbed region of rural Mozambique. Mamm Biol 89:14-20

Sun CC, Fuller AK, Royle JA (2014) Trap configuration and spacing influences parameter estimates in spatial capture-recapture models. PLoS ONE 9:e88025

Suryawanshi KR, Khanyari M, Sharma K, Lkhagvajav P, Mishra C (2019) Sampling bias in snow leopard population estimation studies. Popul Ecol 61:268-276

Williams ST, Williams KS, Lewis BP, Hill RA (2017) Population dynamics and threats to an apex predator outside protected areas: implications for carnivore management. R Soc Open Sci 4:161090

Wilton CM, Puckett EE, Beringer J, Gardner B, Eggert LS, Belant JL (2014) Trap array configuration influences estimates and precision of black bear density and abundance. PLoS ONE 9:e111257

Zimmermann F Foresti D (2016) Capture-recapture methods for density estimation, in: Rovero, F., Zimmermann, Fridolin (Eds.), Camera Trapping for Wildlife Research. Pelagic Publishing Ltd, Exeter, UK, pp. 95-141

Publisher's Note Springer Nature remains neutral with regard to jurisdictional claims in published maps and institutional affiliations. 